\title{
Studi Komparatif Sistem Kendali Bising Aktif Umpan Maju Menggunakan Filter Adaptif Berbasis LMS
}

\author{
Bambang Riyanto ${ }^{1)} \&$ Irma Husnaini ${ }^{2)}$ \\ ${ }^{1)}$ Sekolah Teknik Elektro dan Informatika, Institut Teknologi Bandung \\ ${ }^{2)}$ Teknik Elektro, Universitas Negeri Padang
}

\begin{abstract}
Abstrak. Dalam makalah ini disajikan simulasi dan eksperimen penerapan algoritma filter adaptif berbasis Least Mean Square (LMS) pada sistem kendali bising aktif. Beberapa algoritma adaptif berbasis LMS diteliti, yaitu Preconditioned Least Mean Square (PLMS), Filtered-reference LMS (FxLMS) dan dua varian Filtered-error LMS (FeLMS). Simulasi kendali bisig aktif dilakukan dengan menggunakan rekaman sinyal bising blower. Implementasi dalam eksperimen dilakukan dengan membangkitkan bising yang berasal dari penjumlahan tiga gelombang sinus dengan amplitudo dan frekuensi yang berbeda menggunakan pemroses sinyal digital TMS320C6701 dan melewatkannya melalui jalur primer. Perbandingan keempat algoritma dilakukan dengan mengukur kinerja (tingkat redaman yang dihasilkan) dan kecepatan konvergensi. Hasil simulasi dan eksperimen memperlihatkan bahwa PLMS memberikan kinerja dan kecepatan konvergensi terbaik.
\end{abstract}

Kata kunci: Kendali bising aktif; PLMS; FxLMS; FeLMS; DSP; gangguan stokastik; umpan maju.

\begin{abstract}
In this paper, we discuss simulation and experimental study of the application of Least Mean Square (LMS) based adaptive filter algorithm in active noise control. A number of adaptive filter algorithm based on LMS are investigated, namely Preconditioned Least Mean Square (PLMS), Filteredreference LMS (FxLMS) and two variants of Filtered-error LMS (FeLMS) algorithms. Active noise control simulation for attenuating recorded blower noise is performed. In case of active noise control experiment, a disturbance is generated by adding three sinus waves with different amplitudes and phases using digital signal processor TMS320C6701, and passing them through primary path. Comparison of the four algorithms is carried out by measuring the performance (in terms of resulting attenuation level) and speed of convergence. Simulation and experiment results demonstrate that PLMS provides the best performance and speed of convergence.
\end{abstract}

Keyword: Active noise control; PLMS; FxLMS; FeLMS; DSP; stochastic disturbance; feed-forward. 


\section{Pendahuluan}

Sistem kendali bising aktif (active noise control—selanjutnya disingkat ANC) telah menjadi subjek penelitian dalam beberapa tahun terakhir karena efisien dalam meredam bising, khususnya pada frekuensi rendah. Pada rentang frekuensi rendah ini metoda pasif dengan menggunakan bahan penyerap bising diketahui tidak dapat bekerja dengan efektif. Kendali bising aktif meliputi sistem elektro-akustik atau elektromekanik yang menghilangkan bising primer (yang tidak diinginkan) berdasarkan prinsip interferensi destruktif. Secara spesifik, sinyal anti bising (bising sekunder) dari sumber sekunder yang memiliki amplitudo yang sama dan fasa yang berlawanan dikombinasikan dengan bising primer, sehingga dapat dihasilkan sinyal residu minimum[1,6,813]. Mekanisme ini telah dimungkinkan impelementasinya karena perkembangan yang sangat pesat dari Digital Signal Processor (DSP)[1,8,11]. Tingkat peredaman sinyal bising primer sangat tergantung pada akurasi amplitudo dan fasa dari sinyal anti bising yang dibangkitkan. Karakteristik sumber bising akustik dan lingkungan dalam praktek berubah terhadap waktu, frekuensi, amplitudo, fasa dan kecepatan suara bising bersifat tidak stasioner sehingga sistem kendali bising aktif harus bersifat adaptif agar dapat mengatasi perubahan tersebut.

Algoritma adaptif yang dikembangkan untuk sistem kendali bising aktif umumnya berupa algoritma FxLMS dan algoritma FeLMS[6]. Kedua algoritma ini didasarkan pada metoda steepest descent untuk mengadaptasi koefisien filter. Namun demikian, kecepatan konvergensi algoritma FxLMS dan FeLMS relatif lambat dan konvergensi sinyal dibatasi oleh penyebaran nilai eigen matriks autokorelasi sinyal referensi. Beberapa struktur dan algoritma telah dikemukakan untuk mengatasi masalah kecepatan konvergensi tersebut. Salah satu metoda ini adalah PLMS yang merupakan pengembanggan dari algoritma FxLMS.

Makalah ini menyajikan studi simulasi dan eksperimental beberapa algoritma filter adaptif berbasis LMS pada sistem kendali bising aktif. Studi tentang algoritma PLMS dalam sistem kendali bising aktif telah dilakukan oleh Elliot[4]. Implementasi FxLMS dengan floating point DSP telah dilakukan pada $[8,9]$. Namun demikian, studi pada [4] dilakukan secara terbatas dalam bentuk simulasi dengan menggunakan sinyal bising yang disintesis, sedangkan studi eksperimental oleh B. Riyanto pada [8,9] terbatas pada algoritma FxLMS. Makalah ini mengembangkan lebih lanjut penelitian pada $[4,8,9]$. Secara khusus, kontribusi makalah ini sebagai berikut: 1) mengembangkan studi simulasi yang dilakukan pada [4] dengan menggunakan sinyal yang direkam dari bising blower, 2) membangun sistem kendali bising aktif berbasis DSP dan mengimplementasikan algoritma adaptif berbasis LMS secara real-time dengan 
mengembangkan lebih lanjut hasil penelitian [8,9], dan 3) melakukan eksperimen dengan membandingkan PLMS, dua varian FeLMS dan FxLMS. Beberapa hasil awal penelitian ini disajikan pada [13] yang lebih menekankan pada redaman frekuensi global. Pada makalah ini diteliti juga respons waktu, dan redaman pada frekuensi harmonisanya, disamping redaman frekuensi global, untuk beberapa kasus eksperimen.

Makalah ini diorganisasi sebagai berikut. Pada Bagian 2 didiskusikan sistem kendali bising aktif dengan konfigurasi umpan-maju. Pada bagian ini juga disajikan algoritma filter adaptif, mencakup FxLMS, FeLMS, dan PLMS. Pada Bagian 3 disajikan hasil simulasi sistem kendali bising aktif yang membandingkan ketiga algoritma adaptif tersebut. Pada Bagian 4 disajikan hasil eksperimen dengan menggunakan DSP. Bagian 5 menyimpulkan makalah ini.

\section{Sistem Kendali Bising Aktif Umpan Maju Kanal Tunggal}

Sistem kendali bising aktif dibangun dengan menghasilkan sinyal anti bising (bising sekunder) dari sumber sekunder yang memiliki amplitudo yang sama dan fasa yang berlawanan dengan bising primer. Kombinasi sinyal anti bising dengan bising primer menghasilkan sinyal residu minimum melalui prinsip interferensi destruktif. Pada kendali bising aktif umpan-maju, sebuah sensor digunakan untuk menangkap sinyal bising primer. Sebuah sensor yang lain digunakan untuk menangkap sinyal residu yang merupakan selisih antara sinyal gangguan (sinyal bising setelah melewati jalur primer) dengan keluaran plant. Sinyal referensi (pada umumnya difilter), bersama-sama dengan sinyal galat digunakan untuk mengadaptasi pengendali dalam rangka menghasilkan sinyal anti bising. Dalam impelementasinya sistem kendali bising aktif umpan-maju mencakup dua tahap: 1) tahap pertama mengidentifikasi jalur sekunder, pada umumnya dengan menggunakan struktur FIR dan algoritma LMS, dan 2) tahap kedua menggunakan model FIR jalur sekunder dan struktur adaptif untuk pengendalian [1-6].

\subsection{Algoritma FxLMS}

Terdapat beberapa macam struktur dan algoritma yang telah dikembangkan untuk sistem kendali bising aktif, diantaranya struktur FIR dengan algoritma FxLMS. Algoritma FxLMS didasarkan pada pendekatan steepest descent $[1,4,6]$, dimana penyesuaian koefisien filter dilakukan dengan arah gradien negatif dari permukaan galat pada setiap iterasi. Gambar 1 memperlihatkan blok diagram implementasi algoritma FxMS pada sistem kendali bising aktif. Dalam gambar ini $x(n), d(n), u(n)$, dan $e(n)$ berturut-turut menyatakan sinyal referensi (dari sumber bising), sinyal gangguan (sinyal bising yang telah melewati jalur primer), sinyal kendali (dihasilkan dari aktuator/speaker) dan sinyal galat (diperoleh dari sensor galat/mikrofon). 
Berdasarkan Gambar 1 sinyal keluaran pengendali dapat dirumuskan sebagai

$$
\begin{aligned}
& u(n)=\sum_{i=0}^{I-1} w_{i}(n) x(n-i) \\
& u(n)=w^{T}(n) x(n)
\end{aligned}
$$

Sinyal galat dapat ditulis sebagai

$$
e(n)=d(n)+\sum_{j=0}^{J-1} g_{j} u(n-j)
$$

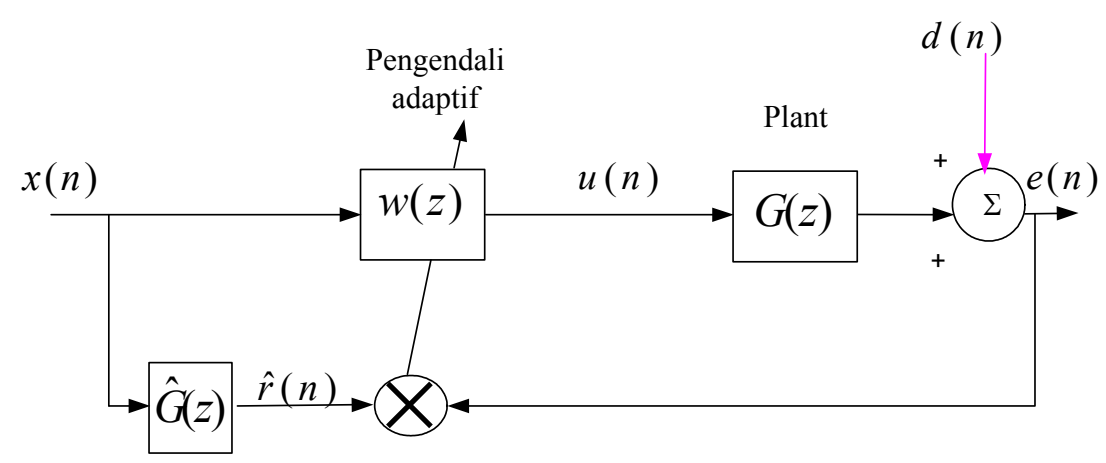

Model plant

Gambar 1 Blok diagram implementasi algoritma FxLMS.

Sinyal galat dapat juga ditulis dalam bentuk

$$
e(n)=d(n)+\sum_{i=0}^{I-1} \sum_{j=0}^{J-1} g_{j} w_{i} x(n-i-j)
$$

Sedangkan sinyal referensi yang terfilter berbentuk

$$
\hat{r}(n)=\sum_{j=0}^{J-1} \hat{g}_{j} x(n-j)
$$

dimana

$$
w=\left[\begin{array}{llll}
w_{0} & w_{1} & \ldots & w_{I-1}
\end{array}\right]^{T}
$$

merupakan vektor koefisien pengendali dan

$$
r(n)=\left[\begin{array}{llll}
r(n) & r(n-1) & \ldots & r(n-I+1)
\end{array}\right]^{T}
$$

merupakan sinyal referensi yang terfilter. Vektor $w$ berubah terhadap waktu sehingga nilainya tergantung pada waktu $n$. Sinyal referensi dalam bentuk vektor dapat juga ditulis sebagai 


$$
x(n)=\left[\begin{array}{llll}
x(n) & x(n-1) & \ldots & x(n-I+1)
\end{array}\right]^{T}
$$

Dengan mengambil bentuk algoritma LMS, algoritma adaptasi dapat ditulis sebagai

$$
w(n+1)=w(n)-\alpha \hat{r}(n) e(n)
$$

dimana $\alpha$ merupakan koefisien konvergensi, $I$ dan $J$ berturut-turut menyatakan orde pengendali adaptif dalam bentuk filter FIR dan orde model plant.

\subsection{Algoritma Filtered-error LMS}

Dalam algoritma FeLMS, sinyal galat difilter melalui delay dan time-reversed model plant untuk menghasilkan sinyal galat yang terfilter. Blok diagram algoritma ini diperlihatkan pada Gambar 2.

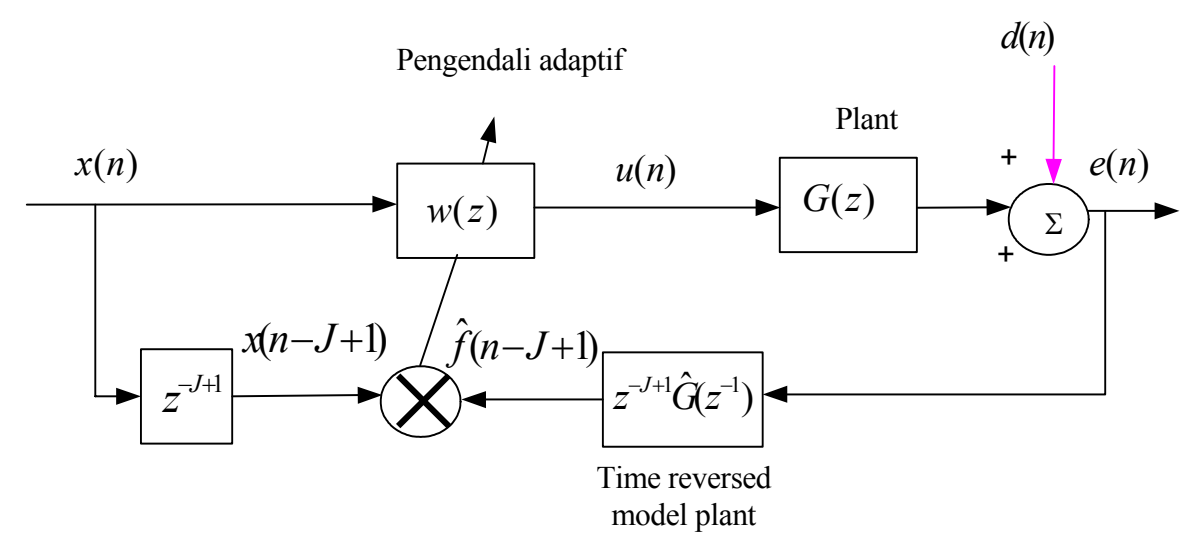

Gambar 2 Blok diagram implementasi algoritma filtered-error LMS.

Persamaan algoritma filtered-error LMS dapat ditulis sebagai berikut

$$
e(n)=d(n)+\sum_{i=0}^{I-1} \sum_{j=0}^{J-1} g_{j} w_{i} x(n-i-j)
$$

Sinyal keluaran pengendali diekspresikan sebagai

$$
u(n)=\sum_{i=0}^{I-1} w_{i} x(n-i)
$$

Algoritma FeLMS ditentukan dengan mengadaptasi koefisien pengendali yang dinyatakan sebagai

$$
w(n+1)=w(n)-o f(n-J+1) x(n-J+1)
$$


dimana

$$
x(n-J+1)=[x(n-J+1), x(n-J) \quad \ldots x(n-J-I+2)]
$$

merupakan sinyal referensi yang tertunda, sedangkan sinyal galat yang terfilter dalam prakteknya sering ditulis sebagai

$$
\hat{f}(n-j+1)=\sum_{j=0}^{J-1} \hat{g}_{J-1-j^{\prime}} e\left(n-j^{\prime}\right)
$$

dimana $\hat{g}_{j}$ merupakan koefisien respons impuls filter FIR model plant yang diasumsikan memiliki $J$ koefisien dan $j^{\prime}=J-j$. Koefisien konvergensi $\alpha$ yang kecil dibutuhkan jika delay plant besar atau time reversed model plant memiliki delay yang cukup besar. Algoritma Filtered-error LMS tidak memiliki keuntungan komputasi dibandingkan dengan algoritma Filtered-x LMS dalam keadaan kanal tunggal. Kinerja yang dihasilkan dan kecepatan konvergensi kedua algoritma ini sebanding $[2,4]$.

\subsection{Algoritma Preconditioned LMS (PLMS)}

Algoritma PLMS merupakan pengembanggan dari algoritma Filtered-error LMS dan merupakan salah satu algoritma yang digunakan untuk mengatasi masalah kecepatan konvergensi. Pada algoritma ini sinyal referensi difilter oleh invers faktrorisasi spektral dari sinyal referensi $F^{-1}(z)$ dalam upaya untuk mempercepat konvergensi, sedangkan invers fasa minimum plant $G_{\min }^{-1}(z)$ dan transpos dari time reverse allpass component $G_{\text {all }}(z)$ digunakan untuk mengkompensasi respons dinamik plant dan koupling antara kanal. Oleh karena itu, algoritma yang dihasilkan disebut Preconditioned LMS (PLMS) atau Filtered-error LMS dengan $F^{-1}(z)$ dan $G_{\min }^{-1}(z)[4,6]$.

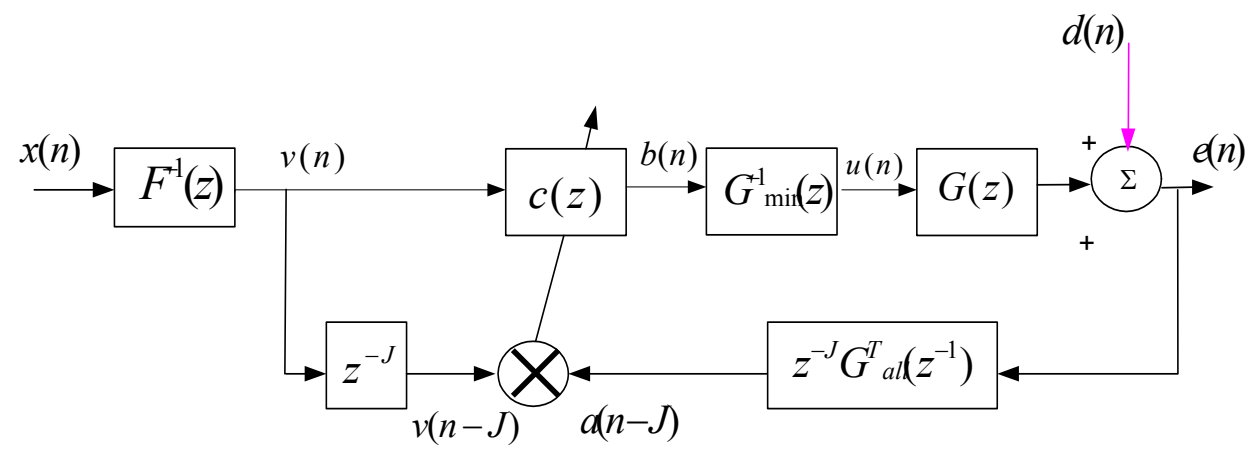

Gambar 3 Blok diagram algoritma preconditioned LMS.

Persamaan algoritma PLMS dapat ditulis sebagai berikut: 
Sinyal galat yang terfilter dapat ditulis sebagai

$$
a(z)=G_{\text {all }}^{T}\left(z^{-1}\right) e(z)
$$

Sinyal referensi yang terfilter dinyatakan dalam bentuk

$$
v(z)=F^{-1}(z) x(z)
$$

Plant $G(z)$ terdiri dari komponen allpass dan komponen fasa minimum, dan oleh karena itu $G(z)$ dapat ditulis sebagai

$$
G(z)=G_{\text {all }}(z) G_{\min }(z)
$$

Komponen allpass dapat dihitung dari $G(z)$ dan $G_{\min }(z)$.

$$
G_{\text {all }}(z)=G(z) G_{\min }^{-1}(z)
$$

dimana

$G_{\min }^{-1}(z) \quad$ invers fasa minimum plant

$F^{-1}(z) \quad$ invers faktorisasi spektral dari matrik densitas spektral sinyal

$c(z) \quad$ referensi

Bentuk algoritma PLMS dalam domain waktu ditentukan dengan mengadaptasi koefisien pengendali yang dinyatakan sebagai

$$
c(n+1)=c(n)-\alpha a(n) v^{T}(n-i)
$$

Agar Persamaan (19) dapat diimplementasikan dengan menggunakan filter kausal, maka $v(n)$ dan $a(n)$ harus ditunda sebagaimana algoritma Filterederror LMS.

\section{$3 \quad$ Hasil Simulasi}

Simulasi dilakukan dengan menggunakan rekaman bising blower sebagai sinyal referensi dan sinyal bising. Penggunaan rekaman bising blower dimaksudkan untuk mendekati kondisi sesungguhnya. Rekaman dilakukan didepan blower dengan menggunakan dua buah mikrofon, satu untuk sinyal referensi dan yang lain untuk sinyal bising dengan jarak masing-masing $1 \mathrm{~cm}$ dan $110 \mathrm{~cm}$ dari blower. Simulasi dilakukan dengan menggunakan perangkat lunak MATLAB. Berikut hasil simulasi untuk proses identifikasi jalur sekunder menggunakan algoritma LMS dengan orde filter FIR $J=100$ dan learning rate $\mu=0.07$. 
Pada simulasi dan eksperimen digunakan frekuensi pencuplikan sebesar $2 \mathrm{KHz}$ (satu iterasi pada kurva respons waktu ekivalen dengan durasi 0.5 milidetik).

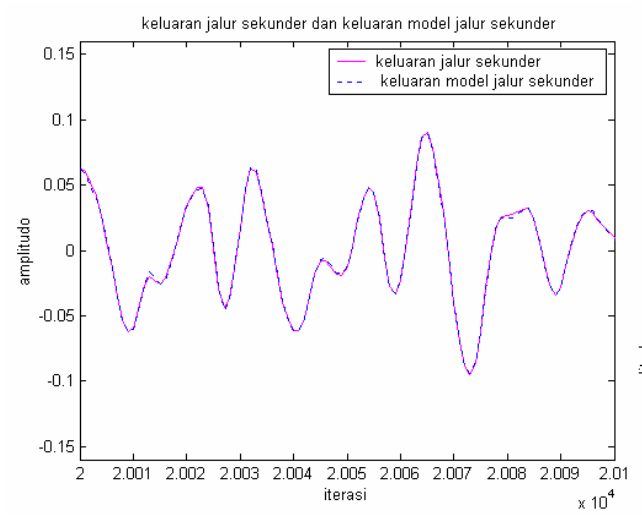

(a)
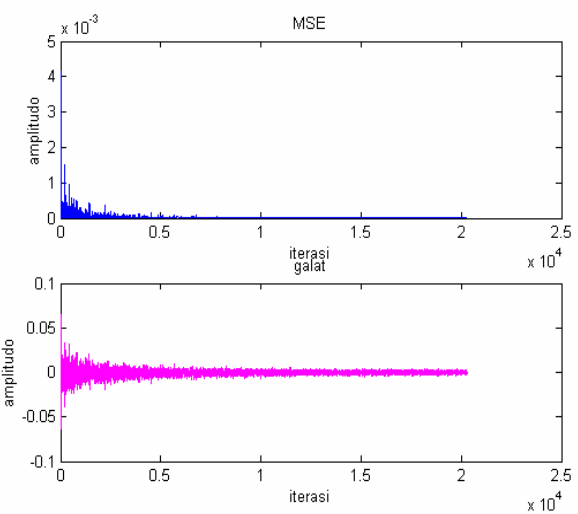

(b)
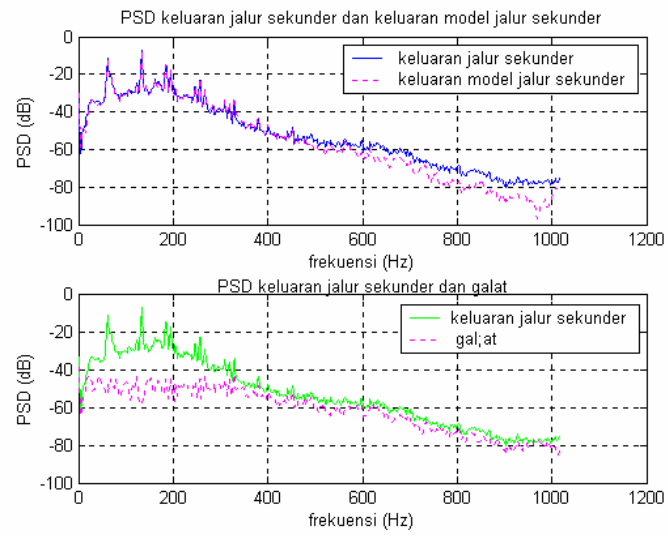

(c)

Gambar 4 (a) Plot keluaran jalur sekunder dan keluaran model jalur sekunder.

(b) Plot MSE dan galat identifikasi.

(c) Plot kerapatan spektrum daya jalur sekunder dan sinyal keluaran model jalur sekunder serta galat.

Berdasarkan Gambar 4 dapat dilihat sinyal keluaran model jalur sekunder dapat mengikuti sinyal keluaran jalur sekunder dengan baik dan sinyal galat dalam keadaan tunak dicapai dalam waktu 2.46 detik. Proses identifikasi menghasilkan model jalur sekunder dengan kesalahan yang dinyatakan dengan MSE (Mean Square Error) $=1.31584 \mathrm{e}-005$ dan SNR(Signal to Noise Ratio) dalam keadaan tunak sebesar $30.0300 \mathrm{~dB}$. Plot kerapatan spektrum daya memperlihatkan respons keluaran model dan plant sekunder sesungguhnya yang mendekati. 
Tahap berikutnya adalah menggunakan model jalur sekunder tersebut pada proses kendali. Hasil simulasi kendali bising aktif diperlihatkan pada Gambar 58. Hasil simulasi tersebut memperlihatkan perbandingan tingkat redaman dan kecepatan konvergensi algoritma filtered-error LMS, filtered-error LMS dengan $F^{-1}(z)$ dan filtered-error LMS dengan $F^{-1}(z)$ dan $G_{\min }^{-1}(z)$ serta algoritma FxLMS.

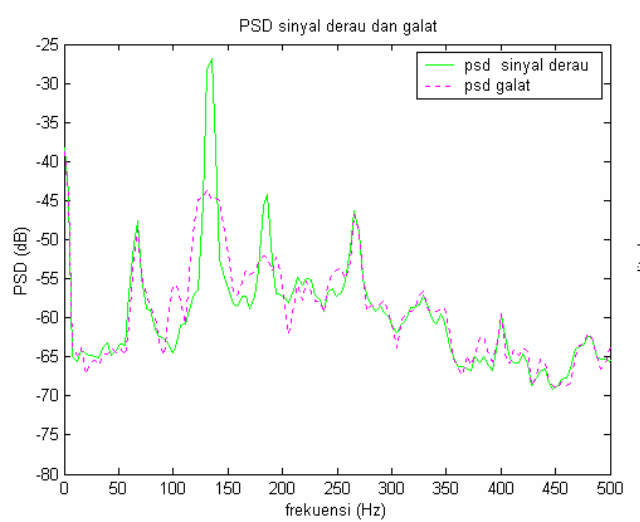

(a)

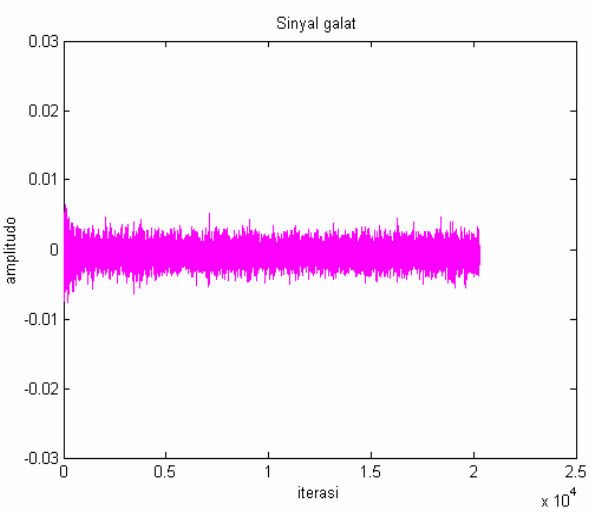

(b)

Gambar 5 Hasil simulasi kendali bising aktif menggunakan algoritma FxLMS. (a) Plot Power Spectrum Density sebelum dan sesudah ANC (b) Plot sinyal galat sesudah ANC.

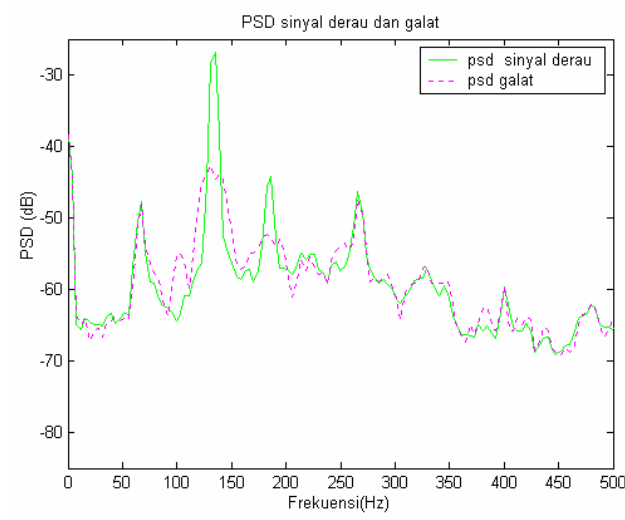

(a)

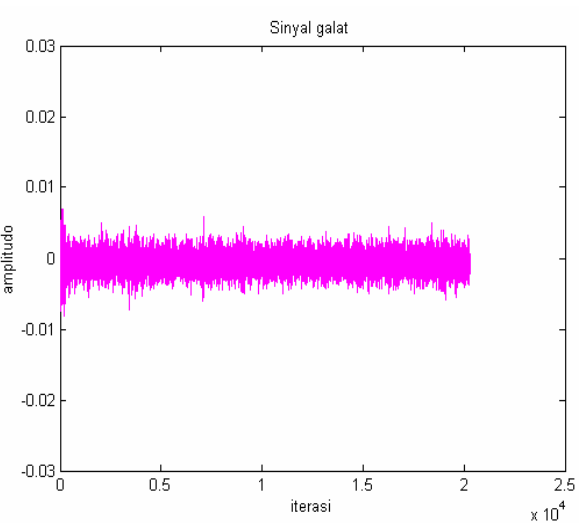

(b)

Gambar 6 Hasil simulasi kendali bising aktif menggunakan algoritma Filtered-error LMS. (a) Plot kerapatan spektral daya sebelum dan sesudah ANC. (b) Plot sinyal galat sesudah ANC. 


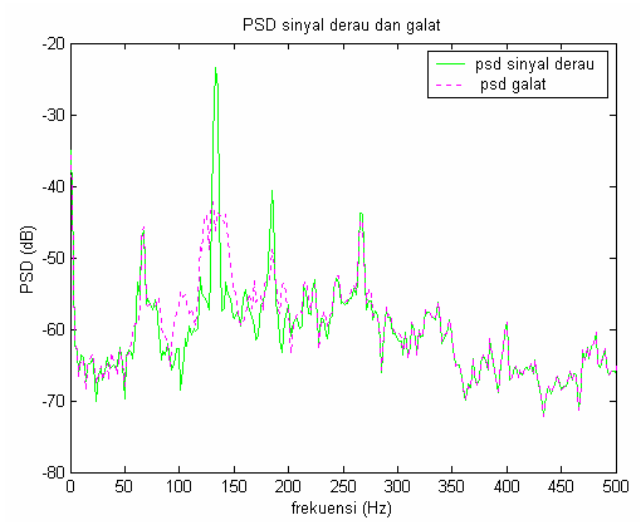

(a)

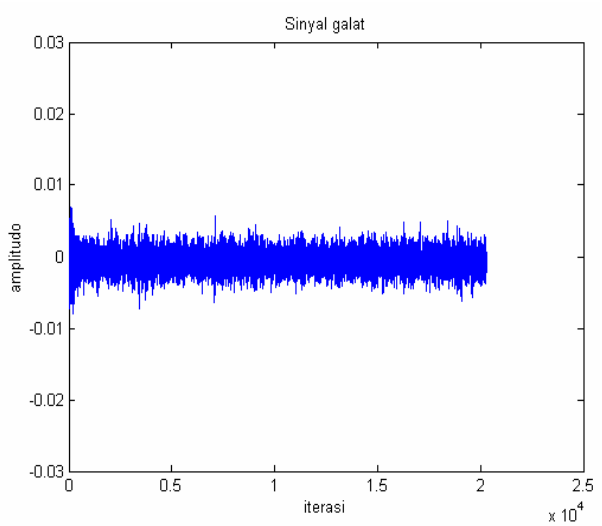

(b)

Gambar 7 Hasil simulasi kendali bising aktif menggunakan algoritma Filtered-error LMS dengan $F^{-1}(z)$. (a) Plot kerapatan spektral daya sebelum dan sesudah ANC dioperasikan. (b) Plot sinyal galat sesudah ANC dioperasikan.

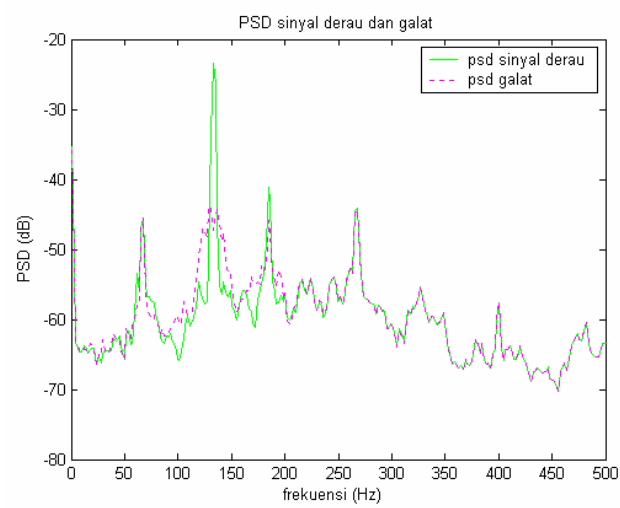

(a)

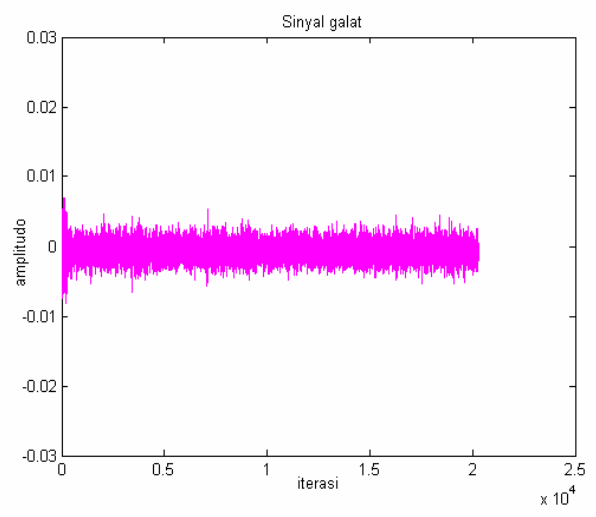

(b)

Gambar 8 Hasil simulasi kendali bising aktif menggunakan algoritma Filtered-error LMS dengan $F^{-1}(z)$ dan $G_{\text {min }}^{-1}(z)$. (a) Plot kerapatan spektral daya sebelum dan sesudah ANC dioperasikan. (b) Plot sinyal galat sesudah ANC dioperasikan.

Tabel 1 memperlihatkan perbandingan redaman yang diperoleh untuk sistem kendali bising aktif umpan maju kanal tunggal dengan menggunakan algoritma Filtered-error LMS dan algoritma FxLMS untuk rekaman bising blower. 
Tabel 1 Perbandingan tingkat redaman dari hasil simulasi.

\begin{tabular}{|c|c|c|c|}
\hline \multirow{2}{*}{ Algorithm } & \multicolumn{2}{|c|}{ Redaman (dB) } & Redaman \\
\cline { 2 - 3 } & $\mathbf{1 3 3} \mathbf{~ H z}$ & $\mathbf{1 8 5} \mathbf{~ H z}$ & Global (dB) \\
\hline FxLMS & 21.9260358 & 8.518252 & 8.193283 \\
\hline Filtered-error LMS & 28.004640 & 9.040656 & 8.1517848 \\
\hline $\begin{array}{c}\text { Filtered-error LMS dengan } \\
F^{-1}(z)\end{array}$ & 29.207417 & 9.431191 & 8.483170 \\
\hline $\begin{array}{c}\text { Filtered-error LMS dengan } \\
F^{-1}(z) \text { dan } G_{\min }^{-1}(z)\end{array}$ & 31.5020980 & 6.461462 & 9.301689 \\
\hline
\end{tabular}

Berdasarkan Tabel 1 dapat dilihat bahwa redaman global terbesar diperoleh dengan menggunakan algoritma Filtered-error LMS dengan $F^{-1}(z)$ dan $G_{\min }^{-1}(z)$ yaitu sebesar 9.301689 dB, diikuti oleh algoritma Filtered-error LMS dengan $F^{-1}(z)$ sebesar $8.483170 \mathrm{~dB}$. Tingkat redaman yang dihasilkan dengan menggunakan algoritma Filtered-error LMS hampir sama dengan algoritma FxLMS. Redaman pada frekuensi $133 \mathrm{~Hz}$ terlihat lebih besar dibandngkan dengan redaman pada frekuensi $185 \mathrm{~Hz}$. Hal ini disebabkan oleh penempatan (lokasi) speaker sedemikian sehingga tidak cukup memberikan eksitasi pada frekuensi di luar frekuensi utama.

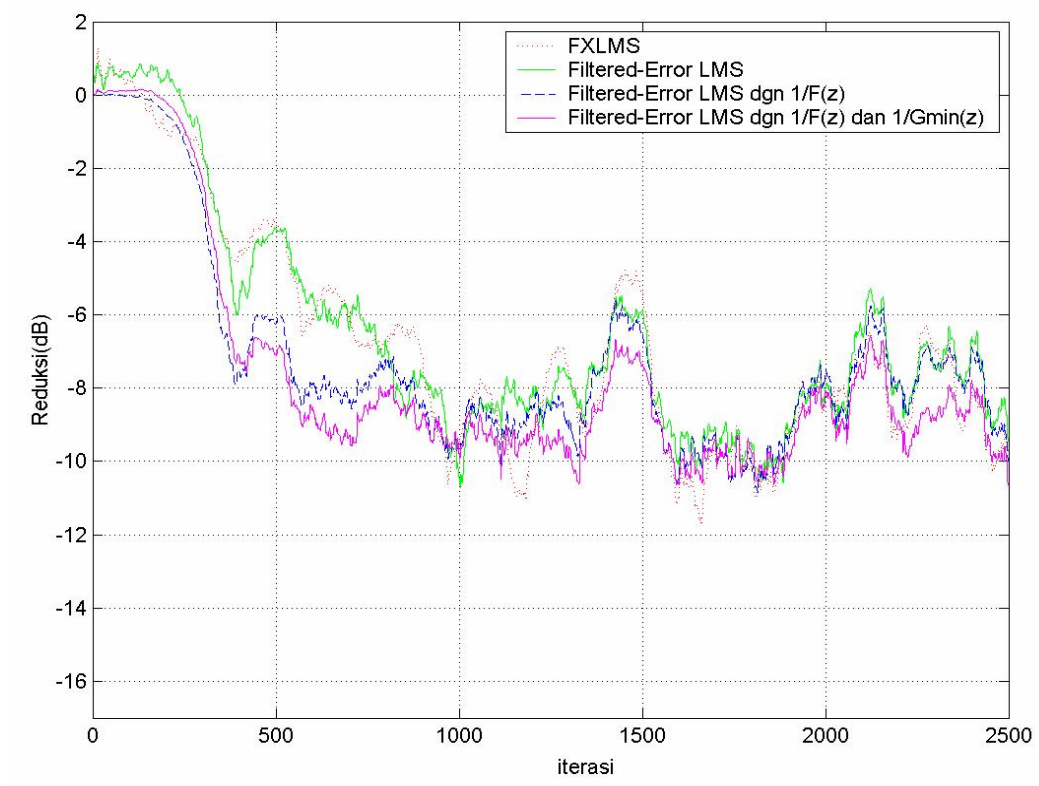

Gambar 9 Perbandingan kecepatan konvergensi diantara keempat algoritma untuk rekaman bising blower. 
Gambar 9 memperlihatkan perbandingan kecepatan konvergensi antara beberapa algoritma Filtered-error LMS dan algoritma FxLMS. Berdasarkan hasil tersebut dapat dilihat algoritma Filtered-error LMS dengan $F^{-1}(z)$ dan $G_{\min }^{-1}(z)$ memiliki kinerja terbaik diikuti oleh algoritma Filtered-error LMS dengan $F^{-1}(z)$. Kecepatan konvergensi algoritma Filtered-error LMS hampir sama dengan algoritma FxLMS, yaitu sekitar 0.3 detik. PLMS menghasilkan kecepatan konvergensi terbaik.

\section{$4 \quad$ Implementasi dan Hasil Eksperimen}

Kendali bising aktif dirancang dan diimplementasikan dengan menggunakan DSP sebagaimana diperlihatkan pada Gambar 10. Sinyal yang ditangkap dari mikrofon diberikan ke pre-amplifier untuk dikuatkan. Sinyal yang dikuatkan ini diberikan ke anti-aliasing filter dan selanjutnya menjadi masukan bagi konverter analog-ke-digital dengan perioda pencuplikan $2 \mathrm{KHz}$. Sinyal digital yang dihasilkan selanjutnya diolah secara adaptif di DSP. Sinyal hasil pengolahan DSP (TMS320C6701) diberikan ke konverter digital-ke-analog. Sinyal analog yang dihasilkan dilewatkan pada low-pass filter dan selanjutnya diperkuat dengan power amplifier untuk menghasilkan sinyal anti bising melalui speaker. Speaker dipilih sedemikian sehingga memiliki karakteristik yang mampu memberikan eksitasi pada frekuensi cukup rendah. Eksperimen sistem kendali bising aktif ini dilakukan di ruang yang relatif terbuka. Bising yang akan diredam dibangkitkan dari penjumlahan tiga gelombang sinus dengan amplitudo dan frekuensi yang berbeda menggunakan DSP. Foto 1 memperlihatkan set-up eksperimen.

Hasil proses identifikasi jalur sekunder menggunakan algoritma LMS dengan orde filter FIR $J=80$ dengan learning rate $\mu=0.07$ diperlihatkan pada Gambar 10.

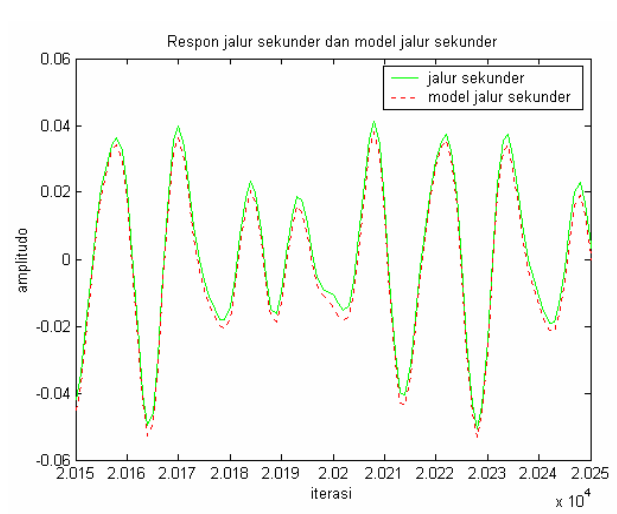

(a)

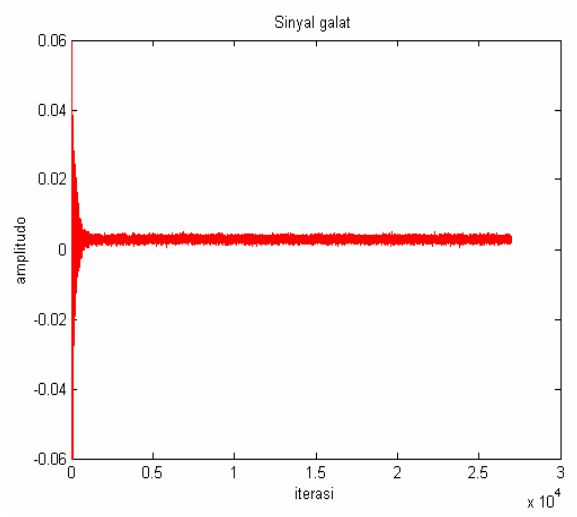

(b) 

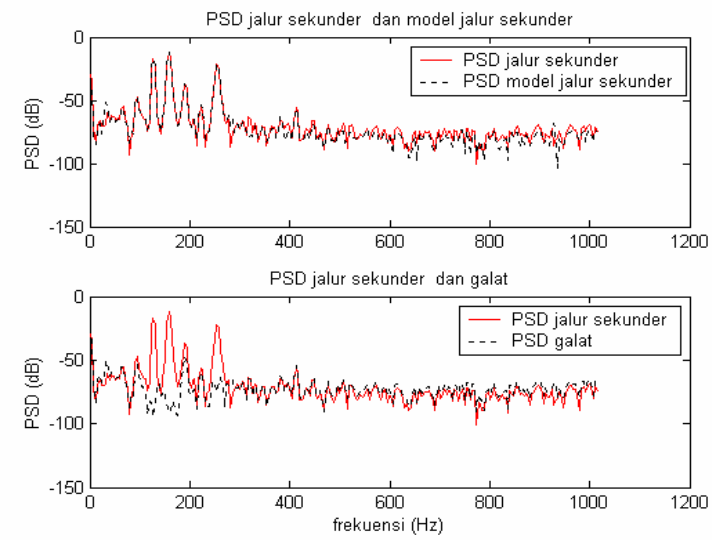

(c)

Gambar 10 (a) Plot keluaran jalur sekunder dan keluaran model jalur sekunder.

(b) Plot galat identifikasi.

(c) Plot kerapatan spektral daya jalur sekunder dan sinyal keluaran model jalur sekunder serta galat .

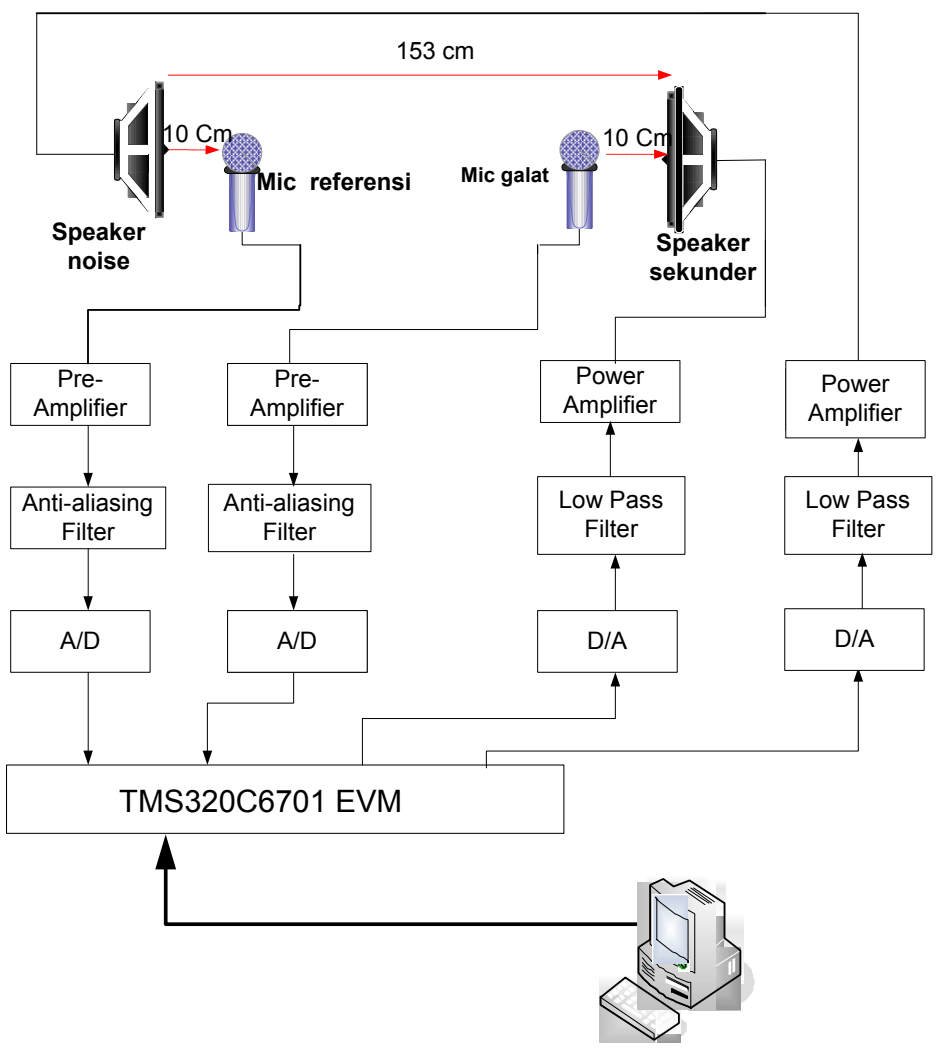

Gambar 11 Geometri percobaan sistem kendali bising aktif kanal tunggal. 
Identifikasi menghasilkan model jalur sekunder dengan kesalahan yang dinyatakan dengan $\mathrm{MSE}=8.9313 \mathrm{e}-006$ dan $\mathrm{SNR}=31.6859 \mathrm{~dB}$.

Geometri implementasi kendali bising aktif diperlihatkan pada Gambar 11. Mikrofon referensi ditempatakan dengan jarak $10 \mathrm{~cm}$ dari speaker sumber bising dan mikropon galat ditempatkan $10 \mathrm{~cm}$ dari speaker anti bising. Jarak antara speaker sumber bising dan speaker anti bising sebesar $153 \mathrm{~cm}$. Penempatan speaker sekunder diupayakan sedemikian sehingga berada pada jarak yang tidak terlalu jauh dari sumber bising sehingga dapat meredam bising pada frekuensi yang cukup tinggi.

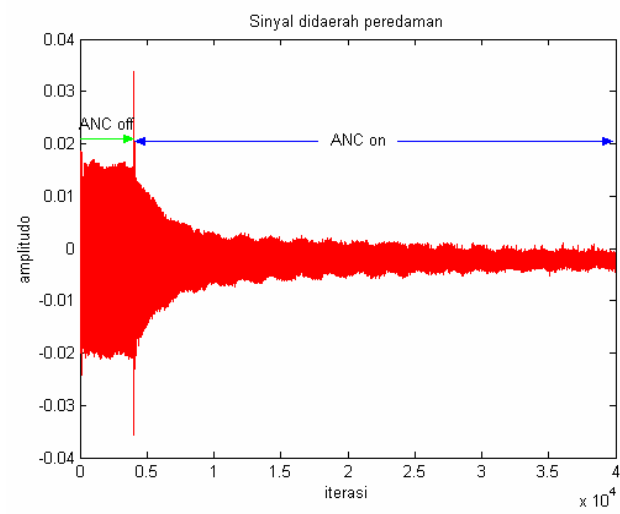

(a)

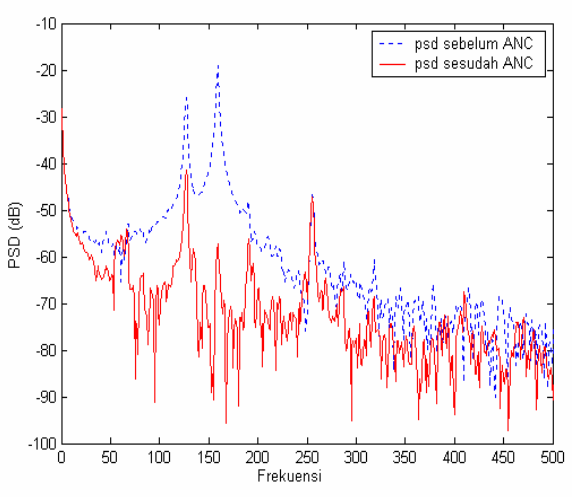

(b)

Gambar 12 Hasil kendali bising aktif menggunakan algoritma FxLMS. (a) Plot sinyal galat sebelum dan sesudah ANC. (b) Plot kerapatan spektral daya sebelum dan sesudah ANC.

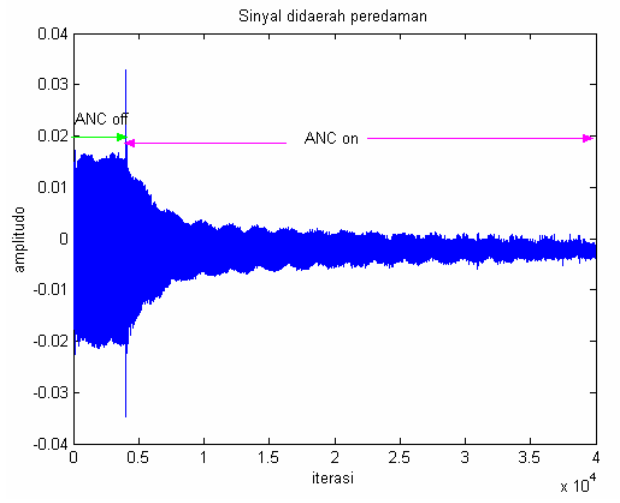

(a)

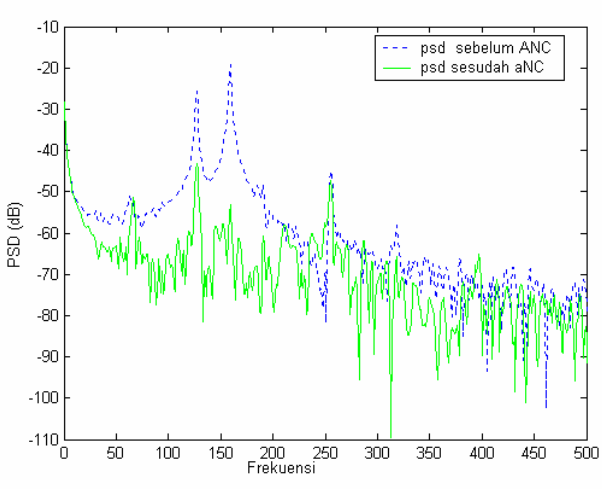

(b)

Gambar 13 Hasil simulasi kendali bising aktif menggunakan algoritma Filtered-error LMS. (a) Plot sinyal galat sebelum dan sesudah ANC. (b) Plot kerapatan spektral daya sebelum dan sesudah ANC dioperasikan. 
Gambar 12-15 berturut-turut memperlihatkan plot sinyal galat dan PSD sebelum ANC dan sesudah ANC dioperasikan dengan menggunakan algoritma Filterederror LMS, Filtered-error LMS dengan $F^{-1}(z)$, Filtered-error LMS dengan $F^{-1}(z)$ dan $G_{\min }^{-1}(z)$ dan algoritma FxLMS.

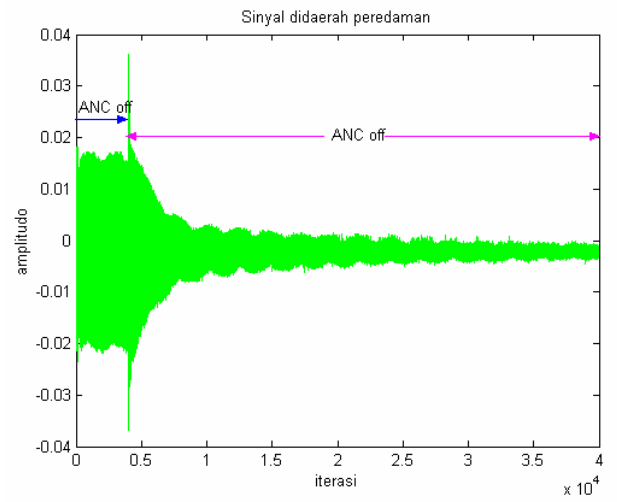

(a)

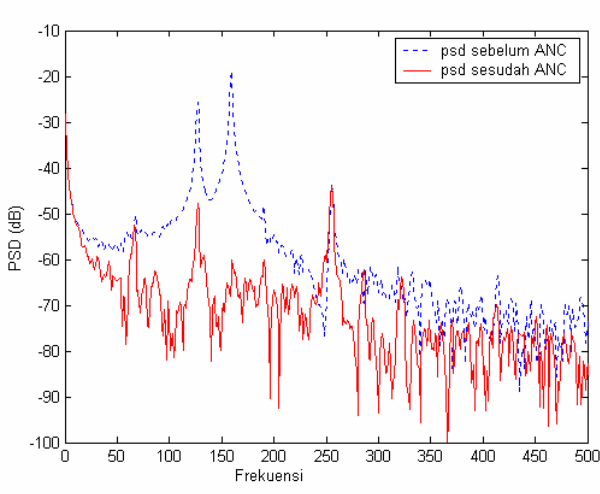

(b)

Gambar 14 Hasil simulasi kendali bising aktif menggunakan algoritma Filtered-error LMS dengan $F^{-1}(z)$. (a) Plot sinyal galat sebelum dan sesudah ANC. (b) Plot kerapatan spektral daya sebelum dan sesudah ANC dioperasikan.

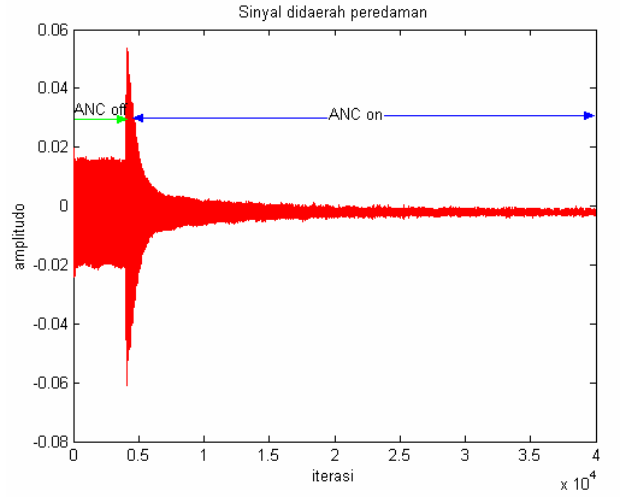

(a)

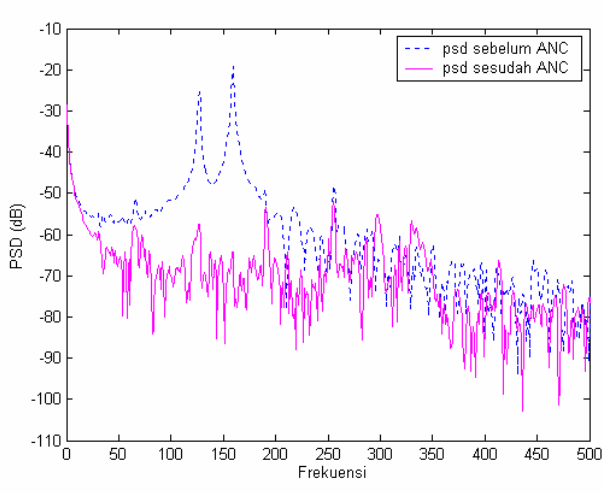

(b)

Gambar 15 Hasil simulasi kendali bising aktif menggunakan algoritma Filtered-error LMS dengan $F^{-1}(z)$ dan $G_{\text {min }}^{-1}(z)$. (a) Plot sinyal galat sebelum dan sesudah ANC. (b) Plot kerapatan spektral daya sebelum dan sesudah ANC dioperasikan.

Pada Tabel 2 diperlihatkan redaman pada sistem kendali bising aktif umpan maju kanal-tunggal dengan menggunakan beberapa algoritma filtered-error LMS dan FxLMS dengan mengubah jarak antara speaker sumber bising dan 
speaker anti bising, yaitu $150 \mathrm{~cm}, 153 \mathrm{~cm}$ dan $160 \mathrm{~cm}$. Frekuensi utama dan harmonisa residu bising pada eksperimen (yaitu 127, dan 159, $255 \mathrm{~Hz}$ ) berbeda dengan simulasi (yaitu 133 dan $185 \mathrm{~Hz}$ ) oleh karena digunakan karakteristik sinyal bising yang berbeda pada kedua kasus.

Tabel 2 Perbandingan tingkat redaman dari hasil eksperimen.

\begin{tabular}{|l|c|c|c|c|c|c|}
\hline Algoritma & Jarak & $\mu$ & $\begin{array}{c}\text { Redaman } \\
\text { Global(dB) }\end{array}$ & $\begin{array}{c}\text { Redaman } \\
\mathbf{1 2 7}(\mathbf{H z})\end{array}$ & $\begin{array}{c}\text { Frekuensi } \\
\mathbf{1 5 9}(\mathbf{H z})\end{array}$ & $\begin{array}{c}\text { Bising (dB) } \\
\mathbf{2 5 5} \mathbf{H z})\end{array}$ \\
\hline \multirow{2}{*}{ FxLMS } & 160 & 0.1 & 17.7737 & 9.7002 & 30.0933 & -2.5329 \\
& 153 & 0.15 & 20.9974 & 15.8468 & 38.5955 & -2.3244 \\
& 150 & 0.18 & 16.5069 & 7.7776 & 33.8089 & -3.6536 \\
\hline Filtered error & 160 & 0.64 & 18.9772 & 19.1424 & 52.5648 & 1.2700 \\
LMS & 153 & 0.58 & 21.5558 & 17.6586 & 37.5820 & 2.1528 \\
& 150 & 0.56 & 18.2636 & 3.5453 & 7.5230 & -1.0853 \\
\hline Filtered error & 160 & 0.28 & 22.7106 & 19.9651 & 26.6685 & -0.7614 \\
LMS dengan & 153 & 0.3 & 23.1364 & 22.8498 & 24.0846 & -4.0682 \\
$F^{-1}(z)$ & 150 & 0.25 & 20.9881 & 14.6331 & 29.6307 & -0.7243 \\
\hline PLMS & 160 & 0.24 & 26.6007 & 30.1538 & 41.9983 & 4.1785 \\
& 153 & 0.22 & 26.6075 & 32.2696 & 51.5637 & 2.5032 \\
& 150 & 0.4 & 25.2983 & 36.9109 & 53.6994 & 0.6778 \\
\hline
\end{tabular}

Hasil eksperimen pada Tabel 2 memperlihatkan redaman global terbesar diperoleh dengan menggunakan algoritma Filtered-error LMS dengan $F^{-1}(z)$ dan $G_{\min }^{-1}(z)$ (sebesar $26.6 \mathrm{~dB}$ ), diikuti oleh algoritma Filtered error LMS dengan $F^{-1}(z)$ (sebesar $23.1 \mathrm{~dB}$ ), algoritma Filtered error LMS (sebesar 21.6 dB) dan algoritma FxLMS (sebesar $21 \mathrm{~dB}$ ). Urutan redaman yang sama diperoleh untuk geometri yang lain. Untuk ketiga kasus ini, yang dibedakan berdasarkan jarak sumber bising dan anti bising, redaman terbaik diperoleh dengan menempatkan speaker anti bising sejauh $153 \mathrm{~cm}$ dari speaker bising.

Gambar 16 memperlihatkan perbandingan reduksi galat diantara algoritma Filtered-error LMS dengan $F^{-1}(z)$ dan $G_{\min }^{-1}(z)$, algoritma Filtered error LMS dengan $F^{-1}(z)$, algoritma Filtered error LMS dan algoritma FxLMS. Dari kurva ini terlihat bahwa bahwa kecepatan konvergensi algoritma FxLMS sama dengan algoritma Filtered-error LMS dengan filter konvergen setelah 15.7 detik. Filtered-error LMS dengan $F^{-1}(z)$ filter mencapai konvergensi setelah 12.3 detik. Kecepatan konvergensi tertinggi diperoleh dengan menggunakan algoritma Filtered-error LMS dengan $F^{-1}(z)$ dan $G_{\min }^{-1}(z)$ yaitu 9.8 detik. 


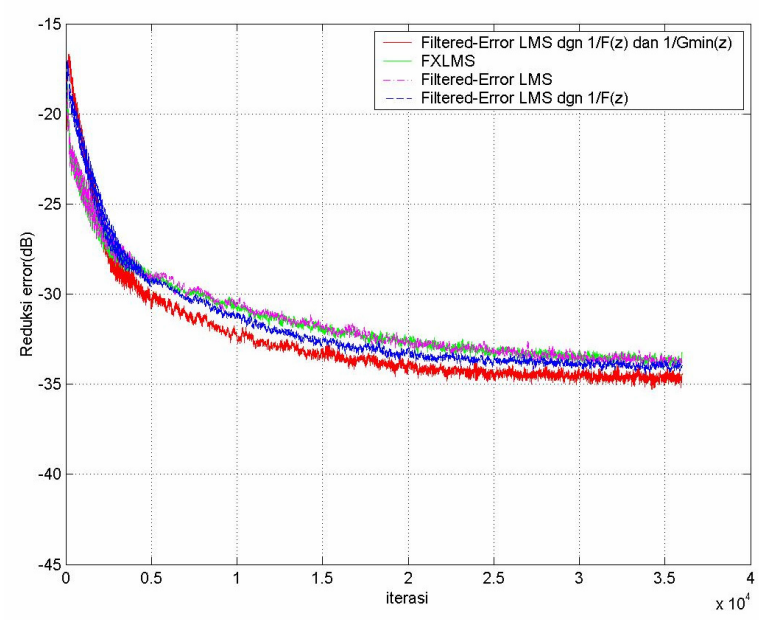

Gambar 16 Perbandingan kecepatan konvergensi diantara keempat algoritma berbasis LMS.
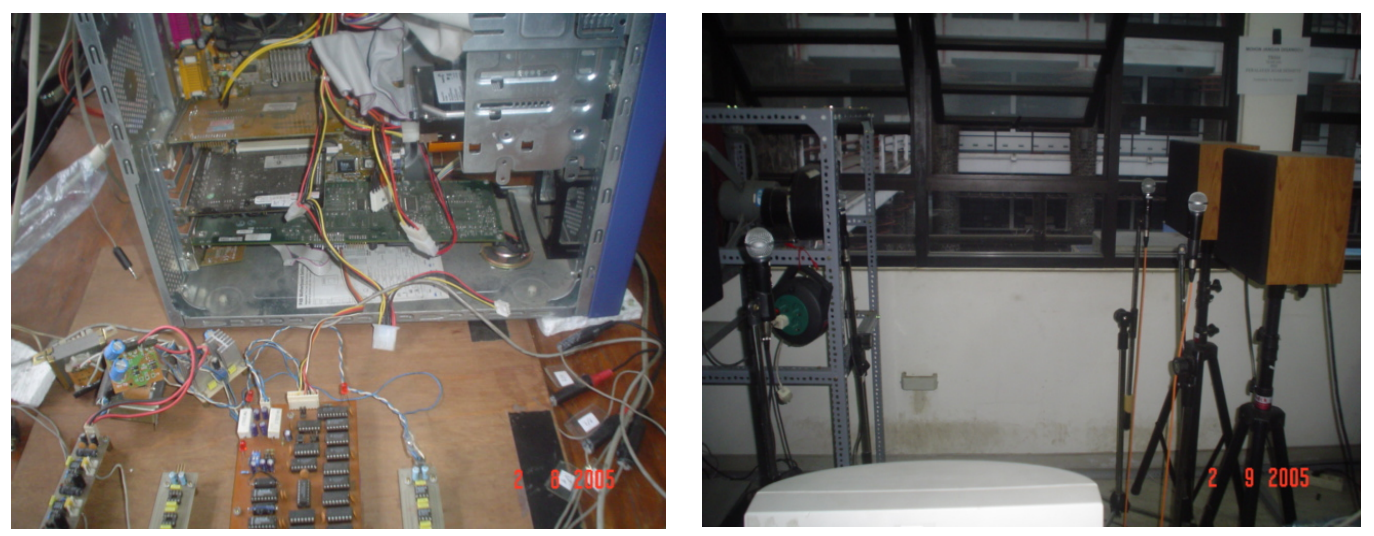

Foto 1 DSP dan antar muka (kiri), set-up eksperimen kendali bising aktif (kanan).

\section{$5 \quad$ Kesimpulan}

Makalah ini telah menyajikan perbandingan algoritma adaptif berbasis LMS pada sistem kendali bising aktif. Kinerja empat algoritma adaptif berbasis LMS telah diteliti dan diukur dari tingkat redaman yang diperoleh serta kecepatan konvergensinya. Perbandingan telah dilakukan dengan menggunakan simulasi dan secara eksperimen dengan menggunakan DSP. Hasil simulasi untuk meredam rekaman bising blower memperlihatkan bahwa kecepatan konvergensi algoritma PLMS paling tinggi dibandingkan ketiga algoritma lainnya. Kinerja terbaik juga diamati pada PLMS yang diukur dari tingkat redaman global. Hasil 
implementasi dengan menggunakan bising yang dibangkitkan menggunakan DSP memperlihatkan algoritma PLMS juga memperlihatkan kinerja dan kecepatan konvergensi yang lebih baik dibandingkan dengan ketiga algoritma lainnya.

\section{Daftar Pustaka}

1. Kuo, S. M. \& Morgan, D.R., Active noise Control Systems: Algoritthms and DSP Implementations, Wiley (1996).

2. Wan, E. A., Adjoint LMS: An efficient alternative to the filtered-x LMS and multiple error LMS algorithms, Proc. Int. Conf. Acoust, Speech, Signal Processing (1996).

3. Vicente, L. \& Masgrau, E., Performance of Two Fast Algorithms for Active Control, Active 99 (1999).

4. Elliott, S. J., Optimal controllers and adaptive controllers for multichannel feedforward control of stochastic disturbances, IEEE Transactions on signal Processing, Vol. 48, No. 4 (2000).

5. Bouchard, M. \& Quednau, S., Multichannel recursive-least-squares algorithms and fast-transversal- filter algorithms for active noise control and sound reproduction systems, IEEE Transactions and Audio Processing, Vol.8.No.5 (2000).

6. Elliott, S. J., Signal processing for Active Control, Academic Press (2001).

7. Bouchard, M. \& Quednau, S., Computational load reduction of fast convergence algorithm for multichannel active noise control, IEEE Trans. Signal Processing 83 (2003).

8. Riyanto, B. \& Nurdin, H.I., DSP Implementation of Adaptive Active Noise Control Inside an Enclosure, Journal of Indonesian Control Systems Society, vol. 4., no. 2 (2001).

9. Riyanto, B., Agustinus, R. \& Soenarko, B., Kendali Aktif Bising Akustik dengan Algoritma FxLMS Hibrid Multikanal, Jurnal Teknoin, Vol. 8, No. 4 (2003).

10. Riyanto, B., Anggono, L.\& Uchida, K., Filtered-X Radial Basis Function Neural Networks for Active Noise Control, Proceedings ITB on Engineering Science, Vol. 36B, No. 1 (2004).

11. Riyanto, B., Anggono, L. \& Uchida, K., DSP Based Modeling and Control for Active Noise Cancellation Using Radial Basis Function Networks, Proc. IEEE Symposium on Intelligent Systems and Control, Vancouver, Canada (2002).

12. Riyanto, B., Yacoub, R.R. \& Uchida, K., Recurrent Neural Networks for Identification of Secondary Path in ANC Using EKF Algorithm, Proc. Asian Control Conference, Melbourne (2004). 
13. Riyanto, B. \& Husnaini, I., Performance Comparison for Broadband Feedforward Active Noise Control System, Proc. ICICI (2005). 